\title{
Identifying and explaining public preferences for the attributes of energy technologies
}

\author{
Frank J. van Rijnsoever*, Jacco C.M. Farla \\ Innovation Studies, Copernicus Institute of Sustainable Development, Utrecht University, P.O. Box 80115, 3508 TC, Utrecht, The Netherlands
}

\section{A R T I C L E I N F O}

\section{Article history:}

Received 30 July 2013

Received in revised form

5 November 2013

Accepted 18 November 2013

Available online 8 December 2013

Keywords:

Social acceptance

Public preferences

Attributes

Energy technology

Use of information sources

Environmental awareness

\begin{abstract}
A B S T R A C T
Public preferences play an important role in the debate about which technologies to include in a future energy system. However, these public preferences for specific technologies are often backed by little knowledge and they may change in different contexts. In this study, we identify a compact set of main attributes for energy technologies (and the energy system as a whole) based on the preferences expressed by a sample of 451 respondents. The preferences for these main attributes are related to the use of different information sources, prior knowledge, environmental awareness, and socio-demographic variables. The results show that 'risk of catastrophe', 'economic security', 'private costs and discomfort', 'spatial impact', and 'price' are the five main attributes that the public discerns. Further, specific information sources can target audiences with specific preferences for the attributes of energy technologies. Prior knowledge (knowing) about energy technologies can induce further the use of information sources, while environmental awareness (caring) promotes making trade-offs between attributes. Based on this research, policymakers can design better strategies to communicate information to the public about technological options and increase awareness about the necessity of changes to the energy system.
\end{abstract}

\section{Contents}

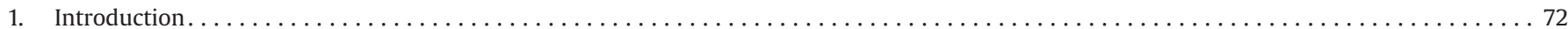

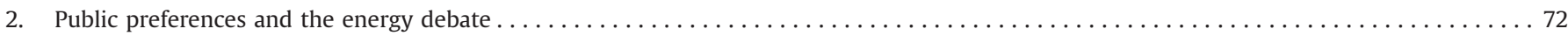

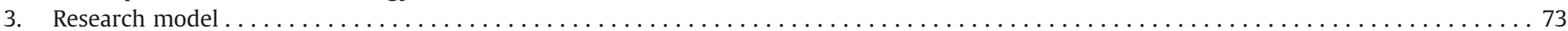

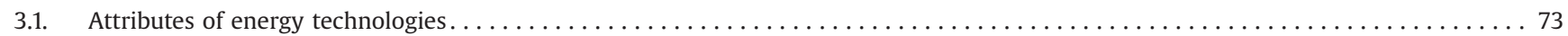

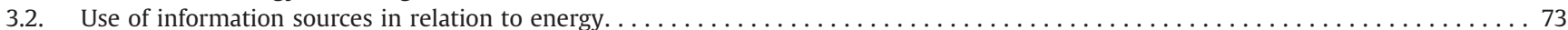

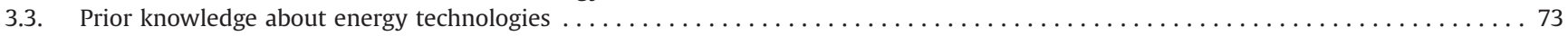

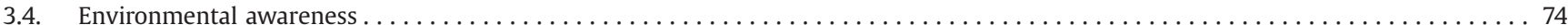

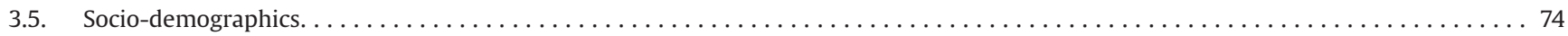

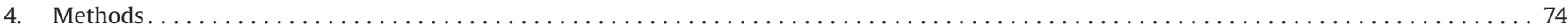

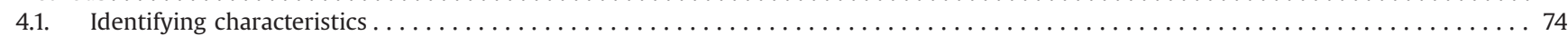

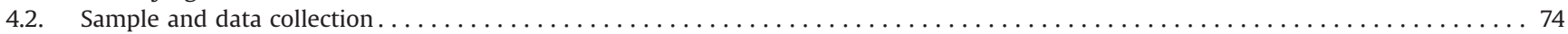

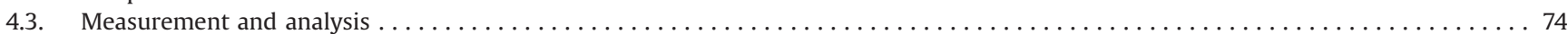

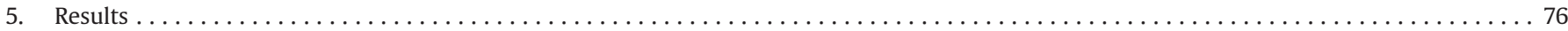

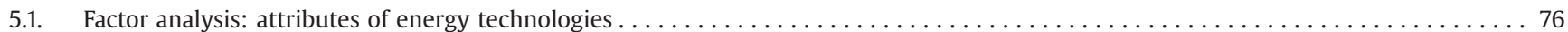

5.2. Model step 1: relating preferences for the attributes of energy technologies to the use of information sources $\ldots \ldots \ldots \ldots \ldots$

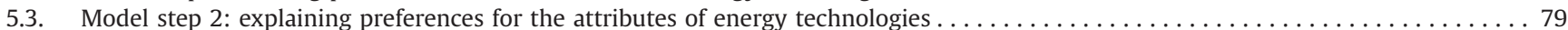

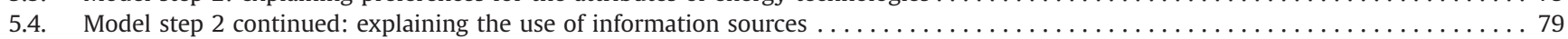

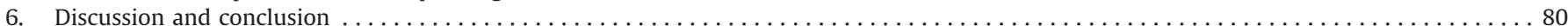

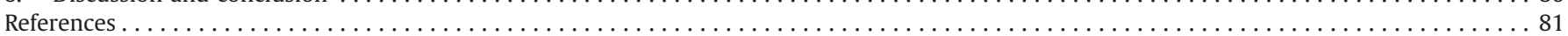

\footnotetext{
*Corresponding author. Tel.: +31 30253 7484; fax: +31302532746.

E-mail addresses: F.J.vanRijnsoever@uu.nl (F.J. van Rijnsoever), J.C.M.Farla@uu.nl (J.C.M. Farla).
} 


\section{Introduction}

The European Union aims to increase the share of renewables in the energy system to $20 \%$ by 2020 [1]. Therefore, many European governments are increasingly using public resources to facilitate the transition from a traditional, fossil fuel-based energy system towards a more sustainable one. The reasons to stimulate this transition process include the growing concern about the effects of greenhouse gas emissions and the increasing energy dependence on politically instable countries $[2,3]$.

Many studies have been conducted that attempt to identify factors that promote or inhibit the transition process [4-6]. A topic that has been less prominent in the transition debate, however, is the issue of the public acceptance of these new energy technologies [7]. However, the topic of public acceptance is becoming increasingly important for a number of reasons. Firstly, the development and promotion of sustainable energy technologies are publicly financed to a large extent. In a society where science is becoming increasingly more accountable to the general public [8,9], the views of the general public have to be taken into account in order to legitimize the innovation process [10]. Recently, it has been argued that the current debate about energy is mainly an elite debate, which fails to engage the opinion of the public [11] or in which it is often unclear how well the opinion of the public is represented [12]. Secondly, in recently liberalized energy markets, demand for a specific type of energy may directly influence the development of these energy sources. Finally, public opinion can be a decisive factor for the failure of a specific energy project $[13,14]$. For the aforementioned reasons, methods have been developed that attempt to manage the social acceptation of energy projects (see [15]).

Studies that look into public preferences as a measure of the acceptance of new energy technologies often limit themselves to a specific technology. Examples include carbon capture and sequestration [16], wind power [17,18], biomass [19,20], solar energy [21], and nuclear power [22,23]. Notable exceptions are the studies by Bergmann et al. [24], Borchers et al. [25], Zoellner et al. [26], Bergmann et al. [27], and Erbil [28] that consider a larger set of energy technologies, and meta-studies that combine the results of public preferences' studies [29]. Studies that consider a broad set of technologies are of great importance given the fact that future energy systems are likely to consist of multiple energy alternatives. They steer the public debate about energy in a more fundamental direction by asking what we want our entire future energy system to look like, instead of focusing on single projects or technologies.

Forming a preference requires making trade-offs between various attributes of the technologies (see for example [17]). Examples of the attributes of (new) energy technologies that were used earlier are the reduction of fossil fuel imports, land use, the creation of employment, and the price paid for energy [24,30]. These attributes are usually identified on an ad hoc basis through document studies and focus group research [24,31]. However, these methods are limited when it comes to generalization; they do not take into account how the population as a whole perceives an attribute. Moreover, in the eyes of the broader population, attributes identified in this manner can have conceptual overlaps. Therefore, it is desirable to identify a list of generic attributes of what the public considers when comparing energy technology options. Identifying this set of generic attributes - from a large sample, in a rigorous quantitative manner - provides a robust input for future studies that estimate preferences for energy technologies. Further, this approach can enrich the public debate and aid policymakers by comparing and choosing between technological alternatives. Finally, when asked for their opinions, individuals usually 'selectively use information that is part of the immediate task description, as well as information that is drawn selectively from memory or from various sources, such as what they've heard, read or seen on the news, to construct a response on the spot' [32]. This means that individuals often lack a full body of knowledge about a technology [14,29], which leads to opinions that can change easily over time [33]. Identifying the most important attributes of energy technologies provides decision criteria that can aid the public when choosing between technological alternatives. The result is that individuals can make wellmeaning and persistent choices. This can strengthen the position of the public and its representatives in the political decisionmaking process.

The aim of this paper is threefold. First, we identify a set of generic attributes that are considered by the public when forming their preferences for energy alternatives. To this end, we reduce the long list of characteristics of energy technologies to a small number of comprehensible and non-overlapping attributes. Second, we aim to explore how these attributes are related to the use of information sources. Including the sources that people use for information gathering is important because it allows actors in the debate to design communication strategies that inform the public about new or existing technologies and supporting policies. Third, by relating the valuation of attributes to variables such as environmental awareness and prior knowledge about energy technologies as well as a set of socio-demographic control variables, we show that the heterogeneity of respondents partly explains preferences for attributes. Therefore, we add to earlier studies that explore heterogeneous preferences in the domain of energy and the environment $[24,27,34,35]$. Further, this enables a better understanding of these preferences and provides opportunities for policymakers and other participants in the energy debate to formulate communication strategies that target specific segments of the population.

Our empirical data consist of a survey with 451 respondents from the Dutch province of Utrecht. In the Netherlands, policies are currently being implemented to guide the transition towards a more sustainable energy system (see [36]), and many experiments with new forms of energy production are being conducted. This makes the Netherlands a suitable research case.

In the following section, we provide a short background on the importance of public preferences for attributes and on how to identify them and we further define the concepts and describe the models used. In Section 3, our empirical research methods are described. The results are presented in Section 4. Finally, Section 5 ends with conclusions and implications.

\section{Public preferences and the energy debate}

Public attention on the negative characteristics of energy production and consumption has increased over the past few decades. Acidification problems due to (coal-fired) power plants received attention in the 1980s and 1990s and led to the increased use of filtering techniques on power plants [37]. The nuclear accidents at Three Mile Island and Chernobyl led to a stagnation in the building of new nuclear power plants in the US and Europe [38]. Currently, the energy debate is largely influenced by the potential climate effects of carbon dioxide emissions resulting from the firing of fossil fuels, although the catastrophe at Fukushima has also reinvigorated the debate about nuclear energy. Increasing the use of renewable energy sources is a potential solution to the climate problem [39].

Many governments strive for an energy system that is clean, safe, and affordable. However, most of the available energy sources have (serious) drawbacks, and no single energy source can resolve all problems. The energy system of the future will therefore (also) be a mix of several energy sources. This means that trade-offs between attributes will have to be made in such a manner that sufficient public support is gathered [40]. Generally, the public 
support for renewable energy is high [41], but it remains unclear which set of energy technologies is preferred and what the support for renewable energy is precisely based on. The societal and political debate is thus about what mix of energy sources would best fit the targets of a sustainable energy system.

This debate is quite difficult for a number of reasons. First, it is impossible to make a 'rational' or 'scientific' choice between energy sources because many facts are uncertain or disputed. Second, preferences are not homogenously distributed, but vary among the population [42]. Third, simply asking people which energy sources or technologies they prefer is inadequate, because the choices would in many cases be based on very partial analyses [43]. At the point of measurement, public preferences are often constructed based on a limited amount of knowledge, situational influences [32], affect images, cultural values [44], motivation [45], and the (sometimes incomplete) set of alternatives presented. The result is that the public opinion found in many surveys does not necessarily represent the real preferences the public actually has.

A partial remedy is to focus on a comparison of the attributes of energy technologies. Despite the fact that individuals are not always able to completely understand the technology as a whole, they are able to understand the individual parts and properties i.e. the attributes - that comprise the technology. This reduces the chance that misunderstandings play a role in the measurement of preferences for a future energy system.

\section{Research model}

This study takes an inductive approach rather than a deductive approach with regard to theory. We discuss preferences for the attributes of energy technologies and explore stepwise how they are related to other concepts. In the first step, we explore the relationship between attribute preferences and the use of information sources. Second, we add prior knowledge, environmental awareness, and socio-demographics to the model as predictors of attribute preferences and the use of information sources. This results in the conceptual model displayed in Fig. 1.

\subsection{Attributes of energy technologies}

Following Blackwell et al. [46], preferences represent attitudes towards one object in relation to another. Preferences for attributes imply that one attribute of a technology is valued over another.

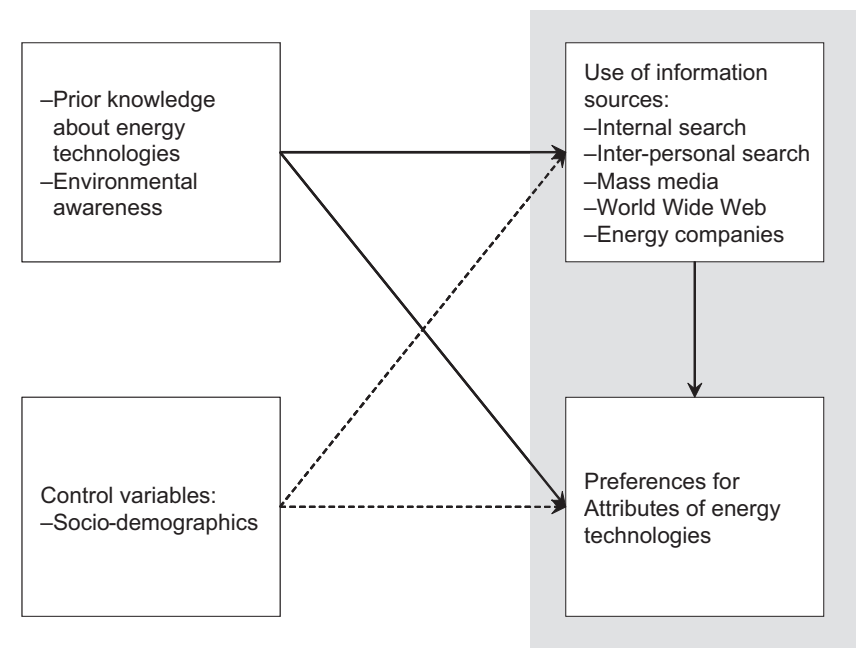

Fig. 1. The conceptual model. First use of information sources is related to preferences for attributes of energy technologies (gray area), second prior knowledge, environmental awareness and socio-demographics are added as predictors.
For example, price might be considered to be more important than environmental impact. To find the relevant attributes, we must take into account all the possible characteristics of a technology that might influence the respondent's acceptance of it. In this paper, we use the term characteristic when we refer to the property of a specific energy technology and the term attribute when we refer to a property that is not specific to a certain technology, but that is framed as a property applicable to all the energy technologies under consideration.

\subsection{Use of information sources in relation to energy}

Preferences are not stable; over time, people can change their opinions, which means that, to a certain extent, preferences are dynamic [47]. People's opinions are influenced by feedback from their own experiences and by external cues, such as communication channels [48]. Van Rijnsoever et al. [42], for example, showed that various types of preferences for automobile attributes are related to the use of information sources by individuals. Relating preferences for attributes to the use of information sources may thus provide opportunities to influence these preferences.

In the literature, two types of information searches are distinguished: internal and external [46]. An internal search is nothing more than an internal memory scan by the individual for decisionrelevant information. An external search is the consulting of external information sources for decision-relevant information. Four external information sources can be identified [42,49]: (1) interpersonal channels; (2) mass media channels; (3) the WWW; and (4) retailers. Interpersonal channels refer to the relations of an individual with people from his or her social environment (e.g. friends, family, and colleagues). Mass media channels are the information sources that do not require direct local interaction with the individual, such as radio, TV, and newspapers. The World Wide Web relates to all information that individuals retrieve from webpages. Retailers are people who advise individuals about energy as part of their profession. In this particular case, the most notable example are energy distribution companies.

\subsection{Prior knowledge about energy technologies}

Prior knowledge is defined as the knowledge that an individual perceives to have about a specific product class. This definition recognizes the difference between objective and subjective knowledge [50-53]. Objective knowledge is the knowledge the individual actually has about a topic, whereas subjective knowledge is the knowledge the individual perceives to have. Generally, individuals tend to overestimate their levels of prior knowledge [53,54]. The level of subjective knowledge in turn is determined by the knowledge the individual actually has (objective knowledge) and the degree of confidence the individual has about the topic [55]; the degree of confidence also partly depends on the level of objective knowledge. Since both knowledge and the level of confidence are important for constructing preferences [32], we use subjective knowledge in the remainder of this paper. Further, in the environmental domain, early research found subjective prior knowledge to be related to proecological behaviors [56], which makes the use of this concept even more relevant for the current topic. In this study, subjective knowledge is related to preferences for attributes about energy technologies and the use of information sources.

Research has shown that subjective knowledge is related to the use of information sources [57,58], although the direction of the relationship is debated [59]. It is often assumed that (socially desirable) public preferences are hampered by a (perceived) knowledge deficit among the public and that education and information provision can improve the formulation of these preferences, although this view has also been criticized [60]. In order to communicate information to the 
public, it is important to relate subjective prior knowledge to the use of information sources.

\subsection{Environmental awareness}

Environmental awareness reflects the extent to which the individual cares about, or is involved with, current environmental problems. The energy debate is often framed in the context of environmental problems. The use of fossil fuels, for example, is often related to climate change. A higher degree of involvement provides extra motivation to the individual to consider his or her preference order [45], which contributes to a better considered final choice. In this paper, we distinguish between attitudinal and behavioral environmental awareness. Previous studies have shown that environmental attitudes and behavior do not always correspond $[42,61]$; therefore, both are considered here. Environmental attitudes are defined in this study as an aggregate construct that captures people's orientation towards the environment in a broad sense [62,63]. Environmental awareness is also related to both preferences for attributes and the use of information sources.

\subsection{Socio-demographics}

Previous studies have also shown that socio-demographic characteristics are associated with search behavior [58,64-68], environmental behavior, and preferences for energy technologies $[24,27,34,35]$. Further, the inclusion of socio-demographics can provide valuable information for targeting a specific audience. The following socio-demographic variables are included: age, gender, education level, income, the number of inhabitants of the town of residence, and homeownership.

\section{Methods}

Before turning to the empirical part, we first describe the general steps to identify the attributes. The first step is to formulate a list of technological alternatives. Important in formulating this list is that it includes all alternatives under consideration. Including only one alternative leads to myopic decision making [32], but leaving out specific technologies (e.g. non-renewable alternatives) can also lead to a bias in attributes. For each technology, one needs to identify an exhaustive list of characteristics that may affect public acceptance. These can be identified through literature studies and interviews. A distinction also needs to be made between technical and service characteristics [69-71]. The public is generally not concerned about technical characteristics, but rather with the effects of these characteristics. For example, a gas-fired plant has the technical characteristic that natural gas is combusted to yield (mainly) water, carbon dioxide, and heat. The latter is converted into electricity. A desired service characteristic is that people have electricity in their houses. An undesired service characteristic is that the emission of greenhouse gases contributes to global warming. Public preferences are measured for such service characteristics.

Next, the list of identified characteristics can then be evaluated by a representation of the population through a structured questionnaire. The main goal is to reduce the long list of characteristics identified to a small number of non-overlapping and comprehensible attributes. Respondents attach a value to each of the characteristics identified, using a rating scale, ranking the characteristics, or in some other form (see [72]). For long lists of characteristics, rating scales are most convenient. Jaccard et al. [72] showed inconsistencies between different methods of preference measurement. It is therefore important to emphasize that the relative value attached to the characteristics is not as important as the covariance between the rated characteristics.
It is vital to minimize the overlap between attributes, because in later analyses an overlap can lead to an overestimation of the importance of a certain attribute. Methods such as factor analysis can be used to identify the overlaps among characteristics and to reduce the number of items to a set of uncorrelated attribute preferences.

After modeling the results, the final step is to interpret the model solution to name the set of attributes in such a manner that a broad audience can relate to it. When interpreting a factor solution, one needs to note that the number of characteristics that load on a certain component says nothing about the importance of the attribute. It only implies that these characteristics were correlated and that therefore there was an overlap. An attribute based on multiple characteristics is as important as an attribute based on one characteristic. Uncorrelated components are latent constructs that can be named based on the characteristic that load on them.

An optional final step is to relate the attributes to other variables, such as the ones presented in our research model. This can be carried out using separate regressions or, preferably, a structural equation model, which takes into account the correlations between the latent dependent variables.

\subsection{Identifying characteristics}

In this study, we take into account nine technologies when identifying characteristics. Each of these is currently in use in the Netherlands, or under consideration for use in the short-term: (1) onshore wind power, (2) offshore wind power, (3) photovoltaic solar power, (4) nuclear power, (5) energy from biomass, (6) energy from natural gas, (7) energy from natural gas with carbon capture and sequestration, (8) energy from coal, and (9) energy from coal with carbon capture and sequestration. We identified 26 service characteristics of energy technologies (Table 1). This list of characteristics was based on an extensive literature study and validated by experts that worked as university researchers in the field of energy technology or energy innovation. The list was then included in a questionnaire administered to a sample of respondents.

\subsection{Sample and data collection}

A total of 800 questionnaires were personally delivered to households throughout the Dutch province of Utrecht. Utrecht is a province in the center of the Netherlands that has 1.2 million inhabitants. The province has two large cities, and numerous (rural) towns and villages of varying size. A few days after delivery, the completed questionnaires were collected. A total of 451 households were surveyed in this manner. Quotas by sex, age, and municipality were used to ascertain a representative sample.

\subsection{Measurement and analysis}

Respondents rated the importance of the 26 technology characteristics on a seven-point Likert scale that varied from very important to very unimportant. A principal component analysis showed that a solution with five latent constructs (e.g. unobserved variables that explain the items in the questionnaire) best fitted the data. This solution was modeled in a confirmatory factor analysis using the LISREL program [73] and the results are presented in Table 1. The explained variance column indicates how much variance the latent construct explains of the original questionnaire item.

To measure the use of information sources, statements were posed about the use of various information sources when gathering information about energy alternatives. Respondents responded on a five-point Likert scale to state from where they received their information. The scale varied from fully disagree to fully agree. 
Table 1

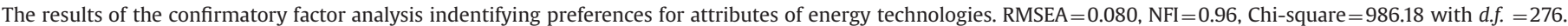

\begin{tabular}{|c|c|c|c|c|}
\hline $\begin{array}{l}\text { Indicator: how important do you find the following aspects } \\
\text { when developing new energy technologies }\end{array}$ & Mean & S.D. & Explained variance & Construct \\
\hline - Risks when storing waste products & 6.08 & 1.32 & 0.74 & \multirow{16}{*}{ Risk of catastrophes (indicator mean: 5.97) } \\
\hline - Negative effects on the general health & 6.18 & 1.29 & 0.42 & \\
\hline - Radioactivity & 6.16 & 1.34 & 0.63 & \\
\hline - Risks when producing the energy & 6.01 & 1.23 & 0.76 & \\
\hline - Storage of waste products & 5.90 & 1.32 & 0.65 & \\
\hline - Vulnerability to terrorist attacks & 5.23 & 1.70 & 0.48 & \\
\hline - Greenhouse gas emissions & 6.04 & 1.13 & 0.54 & \\
\hline - Damage to the ecosystem & 6.13 & 1.24 & 0.53 & \\
\hline - Risks when transporting fuel or waste products & 6.00 & 1.17 & 0.83 & \\
\hline - Indirect economic benefits & 5.19 & 1.22 & 0.41 & \\
\hline - The amount of available fuel in the world & 5.28 & 1.38 & 0.34 & \\
\hline - Direct availability of the technology & 5.05 & 1.38 & 0.45 & \\
\hline - Changes in fuel price & 5.36 & 1.36 & 0.55 & \\
\hline - Additional employment & 5.47 & 1.42 & 0.37 & \\
\hline - Reliable delivery of fuels & 6.06 & 1.05 & 0.54 & \\
\hline - Constant delivery of energy & 5.80 & 1.25 & 0.40 & \\
\hline - Expected lifetime of a technology in the own house & 5.81 & 1.13 & 0.38 & \multirow{6}{*}{ Private costs and discomfort (indicator mean: 5.45 ) } \\
\hline - Return time on investment of technologies in the own house & 5.53 & 1.36 & 0.40 & \\
\hline - Effort it takes to obtain a technology in the own house & 5.33 & 1.48 & 0.45 & \\
\hline - Costs of maintenance of technologies in the own house & 5.50 & 1.27 & 0.66 & \\
\hline - Adjustments made to the own house to accommodate a technology & 5.07 & 1.55 & 0.52 & \\
\hline - Investment costs for a technology in the own house & 5.47 & 1.34 & 0.67 & \\
\hline - Amount of space the technology uses & 5.04 & 1.40 & 0.59 & \multirow{3}{*}{ Spatial impact (indicator mean: 5.33) } \\
\hline - Amount of noise the technology makes & 5.64 & 1.27 & 0.74 & \\
\hline - Effect on landscape & 5.32 & 1.66 & 0.34 & \\
\hline - Price & 5.47 & 1.35 & 1.00 & Price (indicator mean: 5.47) \\
\hline
\end{tabular}

Table 2

The results of the confirmatory factor analysis indentifying different information sources used. RMSEA $=0.082, \mathrm{NFI}=0.94$, Chi-square $=164.62$ with . $f .=44$.

\begin{tabular}{|c|c|c|}
\hline Indicator: I get information about energy alternatives using & Explained variance & Latent construct \\
\hline $\begin{array}{l}\text { - My own experience } \\
\text { - My own knowledge }\end{array}$ & $\begin{array}{l}0.54 \\
0.53\end{array}$ & Internal search \\
\hline $\begin{array}{l}\text { - My close relatives } \\
\text { - My friends } \\
\text { - Other people in my environment }\end{array}$ & $\begin{array}{l}0.58 \\
0.69 \\
0.41\end{array}$ & Interpersonal channels \\
\hline $\begin{array}{l}\text { - Advertisements } \\
\text { - Commercials }\end{array}$ & $\begin{array}{l}0.68 \\
0.53\end{array}$ & Mass media channels \\
\hline $\begin{array}{l}\text { - Websites of energy companies } \\
\text { - Websites of independent organizations } \\
\text { - Search engines }\end{array}$ & $\begin{array}{l}0.69 \\
0.66 \\
0.56\end{array}$ & World wide web \\
\hline $\begin{array}{l}\text { - Representatives of the energy company } \\
\text { - Telephone information lines or helpdesks }\end{array}$ & $\begin{array}{l}0.58 \\
0.87\end{array}$ & Energy companies \\
\hline
\end{tabular}

Table 3

The indicators and measurement model for prior knowledge.

\begin{tabular}{|c|c|c|}
\hline Indicator & Explained variance & Latent construct \\
\hline I know pretty much about various energy technologies & 0.36 & Prior knowledge \\
\hline I do not feel very knowledgeable about various energy technologies ${ }^{a}$ & 0.52 & \\
\hline Among my circle of friends, I am one of the 'experts' on various energy technologies & 0.82 & \\
\hline Compared to most other people, I know less about various energy technologies ${ }^{\mathrm{a}}$ & 0.67 & \\
\hline When it comes to energy technologies, I really do not know a lot ${ }^{a}$ & 0.63 & \\
\hline
\end{tabular}

${ }^{\mathrm{a}}$ Items are reverse scored.

The exact operationalization is provided in Table 2 . The resulting factor solution identified a set of latent constructs that is equal to the classification by Kiel and Layton [65].

Prior knowledge was measured as subjective knowledge, because the choice for an information search channel is based on the (prior) knowledge the individual perceives to have. The concept was measured using the validated subjective knowledge scale of Flynn and Goldsmith [74]. The full measurement model for this construct is presented in Table 3.

Attitudinal environmental awareness was measured using the revised New Environmental Paradigm scale by Dunlap et al. [63]. This validated 15 -item scale contains four components. Since we 
Table 4

The indicators and measurement model for environmental attitudes.

\begin{tabular}{|c|c|c|c|}
\hline Indicator & $\begin{array}{l}\text { Explained } \\
\text { variance }\end{array}$ & Latent sub-construct & Latent construct \\
\hline The earth is like a ship with very limited room and resources & 0.18 & Environmental attitudes sub-construct A & \multirow{11}{*}{$\begin{array}{l}\text { Attitudinal environmental } \\
\text { awareness }\end{array}$} \\
\hline Humans are severely abusing the environment ${ }^{a}$ & 0.45 & (explained variance:0.88) & \\
\hline $\begin{array}{l}\text { If things continue on their present course, we will soon experience a } \\
\text { major ecological catastrophe }\end{array}$ & 0.42 & & \\
\hline $\begin{array}{l}\text { Humans will eventually learn enough about how nature works to be } \\
\text { able to control it }\end{array}$ & 0.56 & $\begin{array}{l}\text { Environmental attitudes sub-construct B } \\
\text { (explained variance:0.19) }\end{array}$ & \\
\hline Human ingenuity will insure that we do NOT make the earth unlivable ${ }^{a}$ & 0.34 & & \\
\hline Humans were meant to rule over the rest of nature ${ }^{a}$ & 0.25 & & \\
\hline $\begin{array}{l}\text { The balance of nature is strong enough to cope with the impacts of } \\
\text { modern industrial nations }{ }^{\mathrm{a}}\end{array}$ & 0.35 & $\begin{array}{l}\text { Environmental attitudes sub-construct C } \\
\text { (explained variance:0.51) }\end{array}$ & \\
\hline $\begin{array}{l}\text { The so-called 'ecological crisis' facing humankind has been greatly } \\
\text { exaggerated }^{\text {a }}\end{array}$ & 0.69 & & \\
\hline $\begin{array}{l}\text { When humans interfere with nature it often produces disastrous } \\
\text { consequences }\end{array}$ & 0.35 & $\begin{array}{l}\text { Environmental attitudes sub-construct D } \\
\text { (explained variance:0.45) }\end{array}$ & \\
\hline The balance of nature is very delicate and easily upset & 0.41 & & \\
\hline Plants and animals have as much right as humans to exist & 0.26 & & \\
\hline
\end{tabular}

${ }^{\mathrm{a}}$ Items are reverse scored $(\mathrm{NFI}=0.90, \mathrm{RMSEA}=0.068)$.

only wanted one construct for environmental attitudes, a secondorder latent construct was modeled based on the four components shown using a principal component analysis. ${ }^{1}$ As model performance indicators, we used the Normed Fit Index (NFI) and Root Mean Square Error of Approximation (RMSEA). Based on these, a separate confirmatory factor analysis indicated a good fit with the data $(\mathrm{NFI}=0.90, \mathrm{RMSEA}=0.068)$. The confirmatory factor analysis was incorporated in the final model. The full measurement model for this construct is presented in Table 4.

Behavioral environmental awareness was measured as the number of environmentally friendly behaviors the respondent displayed. The following behaviors were measured: (1) buying 'green electricity' (e.g. renewable), (2) having more than three energy-saving light bulbs, (3) having a condensing boiler, (4) having a water-saving shower head, (5) having a solar boiler, (6) having solar panels on the roof, and (7) being a member of an environmental movement.

With regard to socio-demographics, the following observations were made. Age was measured in years (mean $=44.71$, standard deviation (S.D.) =16.69). Women were a little overrepresented (53.9\% of respondents). Education level was measured on an ordinal scale, which represented the categories in the Dutch educational system. The sample was slightly too highly educated, which is common in survey data. Income was measured on a seven-point ordinal scale with monthly household income categories after tax and social security contributions. The median income category was between 2001 and 3000 Euros monthly. The number of inhabitants was measured on an ordinal four-point scale. The median was between 10,000 and 50,000 inhabitants. Finally, $71 \%$ of respondents indicated that they owned their homes. This means that homeowners were overrepresented in this sample; the percentage of homes owned in the province of Utrecht is $59 \%$ [75]. This is probably due to a slight overrepresentation of respondents in rural areas.

The constructs were related to each other according to Fig. 1 in the form of a structural equation model using the LISREL program [73]. The model was estimated in two steps: the first step relates the use of information sources to preferences for the attributes

\footnotetext{
${ }^{1}$ Indicators with a factor loading lower than 0.3 or that did not load clearly on only one of the four components were discarded. This happened to four of the original 15 items.
}

of energy technologies (indicated with a gray area in Fig. 1). The second step expands this model by adding prior knowledge, environmental awareness, and socio-demographics. In the models, we allowed for covariance among the information channel variables and attitudinal constructs. In addition, error covariances among the indicators were allowed if the modification indicated that this would significantly improve the model fit; this did not influence the main relationships between the constructs in the model. As model performance indicators, the RMSEA, NFI, and model chi-square with degrees of freedom (d.f.) were used.

\section{Results}

\subsection{Factor analysis: attributes of energy technologies}

Table 1 also shows the results of the confirmatory factor analysis. Preferences for five attributes when assessing energy technologies were described. When examining the factor means, it can be seen that respondents attach a relatively high importance to all characteristics of energy technologies. This indicates a general concern about energy problems.

The latent constructs that we derived from the analysis were:

1. Risk of catastrophes: people scoring high on this construct are concerned about the potentially catastrophic consequences a technology might have. It is interesting that people who value environmental aspects as important are also more likely to value the risk aspects of the technology as important. This contains all the aspects that Slovic [76] identified in the risk perceptions of nuclear energy (e.g. unknown, dread, uncontrollable, inequitable, catastrophic, and likely to affect future generations). This finding could be the result of media campaigns that frame environmental problems in terms of potentially uncontrollable risks and catastrophes.

2. Economic security: people scoring high on this construct find it important that a constant supply of energy is provided to the country. It mainly focuses on energy security and macroeconomic issues. It also expresses concerns raised in public debate about increasing energy dependence on politically instable countries (see $[2,3]$ ).

3. Private costs and discomfort: this construct reflects the perceived costs individuals have to incur in order to obtain energy 
Table 5

The partial correlation matrix.

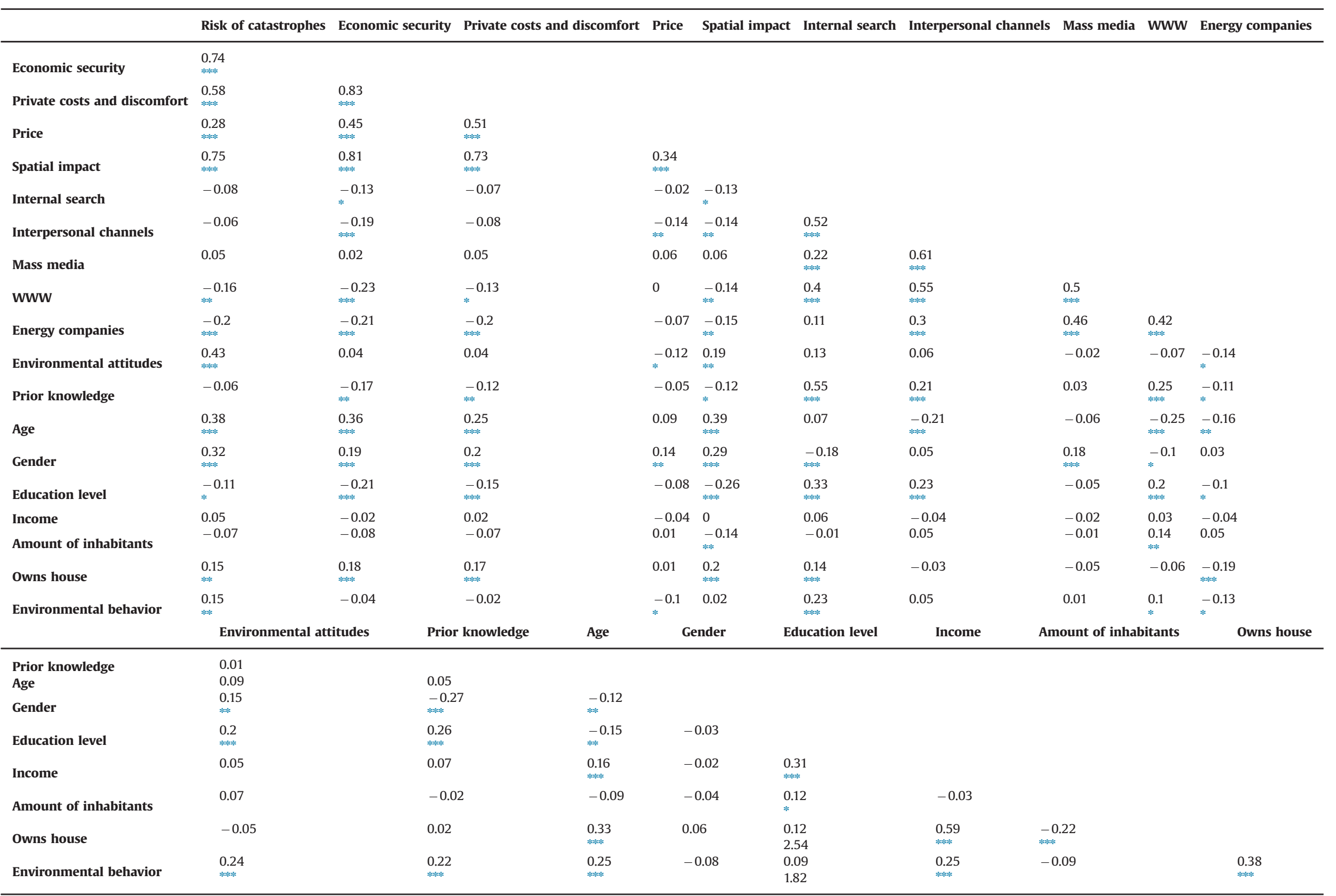

$$
\begin{aligned}
& \begin{array}{l}
* p<0.05 . \\
* * p<0.01
\end{array} \\
& \text { *** } p<0.01 \text {. }
\end{aligned}
$$


from a specific technology. People scoring high on this construct find it important that they do not suffer any discomfort and have low transaction costs when adopting an alternative form of energy. This is mainly an issue with the domestic micro-generation of energy; obtaining these micro-generated alternatives requires active effort (e.g. searching for information about subsidies), which can be a barrier to successful implementation [77]

4. Spatial impact: people scoring high on this construct are concerned about the impact the technology might have on landscapes and the local environment. The prime technological example that has this attribute is onshore wind power [18].

5. Price per kWh did not load on any of these constructs as characteristic. This characteristic is therefore modeled as a separate construct. This reflects the economic competiveness of an alternative and is an important attribute in public debate on all technologies.

These constructs represent a set of attributes that are theoretically distinct and that apply to all the energy alternatives currently under consideration. The principal component analysis modeled the five attributes as uncorrelated constructs, while the confirmatory factor analysis (which allows covariance among the constructs) showed that the constructs are distinct but related. The partial correlation matrix between all latent variables (see [78]) is presented in Table 5. The correlation matrix shows that the constructs are all positively related to each other, although some more strongly than others.

\subsection{Model step 1: relating preferences for the attributes of energy technologies to the use of information sources}

Table 6 presents the standardized estimators of the first model step; each column presents a different dependent variable. The explained variances are relatively low, indicating that the use of information sources is only mildly associated with preferences for the attributes of energy technologies. A general trend that can be discerned is that people who use mass media generally score higher on all attributes, while people who make more use of energy companies value the attributes as less important. This finding indicates that people who use more mass media are also more concerned about energy problems, while people that consult energy companies are less concerned.

Table 6

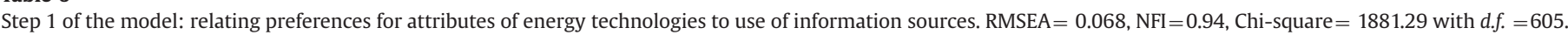

\begin{tabular}{|c|c|c|c|c|c|}
\hline & \multicolumn{5}{|c|}{ Preferences for attributes of energy technologies } \\
\hline & Risk of catastrophes & Economic security & Private costs and discomfort & Spatial impact & Price \\
\hline Internal search & -0.04 & 0.04 & 0.05 & 0.15 & -0.03 \\
\hline Interpersonal channels & -0.04 & $-0.23^{* * *}$ & -0.15 & $-0.20^{*}$ & $-0.50^{\text {**k:k }}$ \\
\hline Mass media & $0.28^{* * *}$ & $0.32^{* * * *}$ & $0.24^{* * *}$ & $0.33^{* * *}$ & $0.39^{* * *}$ \\
\hline WWW & -0.14 & $-0.15^{*}$ & -0.06 & -0.10 & 0.11 \\
\hline Energy companies & $-0.25^{* * * *}$ & $-0.18^{* * *}$ & $-0.20^{* * * * *}$ & $-0.17^{*}$ & $-0.16^{*}$ \\
\hline$R^{2}$ & 0.09 & 0.14 & 0.09 & 0.09 & 0.08 \\
\hline
\end{tabular}

$$
\begin{aligned}
& * p<0.05 \\
& * * p<0.01 \\
& * * * p<0.001 .
\end{aligned}
$$

Table 7

\begin{tabular}{|c|c|c|c|c|c|c|c|c|c|c|}
\hline & $\begin{array}{l}\text { Risk of } \\
\text { catastrophes }\end{array}$ & $\begin{array}{l}\text { Economic } \\
\text { security }\end{array}$ & $\begin{array}{l}\text { Private costs } \\
\text { and discomfort }\end{array}$ & $\begin{array}{l}\text { Spatial } \\
\text { impact }\end{array}$ & Price & $\begin{array}{l}\text { Internal } \\
\text { search }\end{array}$ & $\begin{array}{l}\text { Interpersonal } \\
\text { channels }\end{array}$ & $\begin{array}{l}\text { Mass } \\
\text { Media }\end{array}$ & WWW & $\begin{array}{l}\text { Energy } \\
\text { companies }\end{array}$ \\
\hline \multicolumn{11}{|l|}{ Use of information sources } \\
\hline Internal search & $-0.19^{*}$ & 0.02 & 0.05 & -0.12 & $0.21^{*}$ & & & & & \\
\hline Interpersonal channels & 0.04 & -0.18 & -0.07 & -0.10 & $-0.36^{* * *}$ & & & & & \\
\hline Mass media & 0.04 & $0.23^{*}$ & 0.15 & 0.08 & $0.23^{*}$ & & & & & \\
\hline WWW & 0.09 & 0.00 & 0.07 & $0.18^{*}$ & 0.15 & & & & & \\
\hline Energy companies & $-0.14^{* * *}$ & $-0.22^{\text {*冰* }}$ & $-0.27^{* * * * *}$ & $-0.14^{*}$ & $-0.19^{* * *}$ & & & & & \\
\hline \multicolumn{11}{|l|}{ Environmental awareness } \\
\hline $\begin{array}{l}\text { Environmental } \\
\text { attitudes }\end{array}$ & $0.43^{* * * *}$ & 0.09 & 0.05 & $0.25^{* * k * *}$ & $-0.14^{*}$ & $0.13^{*}$ & 0.07 & 0.00 & -0.08 & -0.11 \\
\hline $\begin{array}{l}\text { Environmental } \\
\text { behavior }\end{array}$ & -0.04 & $-0.15^{* * *}$ & $-0.13^{*}$ & $-0.15^{* * *}$ & $-0.12^{*}$ & 0.05 & 0.04 & 0.04 & $0.14^{* * *}$ & -0.02 \\
\hline Prior knowledge & 0.10 & -0.09 & -0.08 & 0.04 & -0.08 & $0.46^{\text {***⿰㇇⿰亅⿱丿丶丶 }}$ & $0.19^{* * *}$ & 0.10 & $0.19^{* * * *}$ & -0.07 \\
\hline \multicolumn{11}{|l|}{ Socio-demographics } \\
\hline Age & $0.36^{* * * *}$ & $0.29^{\text {***** }}$ & $0.21^{* * *}$ & $0.37^{* * *}$ & 0.10 & -0.02 & $-0.21^{* * * *}$ & -0.03 & $-0.26^{* * * *}$ & $-0.11^{*}$ \\
\hline Gender & $0.30^{* * * *}$ & $0.14^{* *}$ & $0.18^{* * * *}$ & $0.28^{* * * * *}$ & 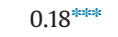 & -0.07 & 0.07 & $0.21^{* * * *}$ & -0.05 & 0.02 \\
\hline Education level & $-0.12^{*}$ & -0.10 & $-0.13^{*}$ & $-0.21^{* * * *}$ & -0.02 & 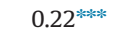 & $0.17^{* * *}$ & -0.08 & 0.10 & -0.10 \\
\hline Income & -0.02 & $-0.13^{*}$ & -0.02 & -0.09 & -0.03 & $-0.17^{* * *}$ & $-0.15^{*}$ & 0.08 & 0.02 & $0.14^{*}$ \\
\hline Amount of inhabitants & 0.03 & 0.01 & 0.00 & -0.07 & 0.03 & 0.00 & 0.03 & -0.01 & $0.11^{*}$ & 0.02 \\
\hline Owns house & 0.10 & 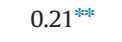 & $0.14^{*}$ & $0.20^{* * *}$ & 0.02 & $0.19^{* * *}$ & 0.11 & -0.14 & -0.04 & $-0.20^{* *}$ \\
\hline$R^{2}$ & 0.48 & 0.30 & 0.20 & 0.40 & 0.14 & 0.39 & 0.14 & 0.05 & 0.17 & 0.08 \\
\hline
\end{tabular}

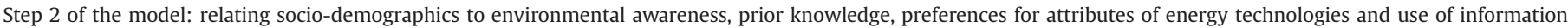
sources. $\mathrm{RMSEA}=0.067, \mathrm{NFI}=0.87$, Chi-square $=4772.41$ with d.f. $=1589$.

\footnotetext{
$* p<0.05$.

$* * p<0.01$.

$* * * * 0.001$.
} 
Further, people making more use of interpersonal channels are less concerned about economic security, spatial impact, and price. For these respondents, the risk of catastrophes and private costs and discomfort are thus relatively more important attributes. Finally, people making more use of the WWW value economic security less. These results indicate that (1) the use of mass media and energy companies is related to a general concern about the energy issue and (2) interpersonal channels and the WWW are the channels that discriminate best among the preferences.

\subsection{Model step 2: explaining preferences for the attributes of energy technologies}

In step 2 (Table 7), the environmental awareness variables, prior knowledge, and socio-demographics are added to the model as predictors of both preferences for the attributes of energy technologies and the use of information sources. The addition of these variables leads to a substantial increase in the explained variance. The improvement in the explained variance for attribute preferences can mainly be attributed to environmental awareness and, to a lesser extent, socio-demographics.

A consequence of adding the variables in step 2 is that most of the relationships between preferences for attributes and the use of information sources disappear. Using energy companies remains negatively related to most attribute preferences, except for spatial impact. In addition, interpersonal channels remain negatively related to price.

Further, some small new significant effects appear. Internal search is negatively related to the risk of catastrophes. This finding indicates that people making less use of external sources are less concerned about the long-term risks of energy technologies. Given the strong relationships between internal search and prior knowledge or education level, this could be the result of an information deficit. Internal search is also related to price. People relying strongly on their own experiences are thus more concerned about the price they pay for energy. The use of the WWW for information is positively related to spatial impact and price, but these effects are relatively small in terms of the explained variance.

Environmental attitudes are strongly related to the risk of catastrophes. This finding is unsurprising since some of the items in this attribute construct were related to the environment. It is interesting that environmental attitudes are also positively related to spatial impact, but negatively related to price. Here, we see an interesting trade-off. When controlling for socio-demographic characteristics, people with high environmental attitudes find it important that future energy technologies have a low risk of catastrophes and low spatial impact, while they value the price they pay for their energy less. Further, there are negative relationships between environmental behavior and all attributes except the risk of catastrophes. This finding indicates that people who display environmental behavior have different preferences than those with high environmental attitudes.

Age and gender are related to all preferences for attributes, except price. This finding indicates that older people and women are more concerned about the energy problem in general, which is in line with the findings that women perceive risks in general higher than men $[79,80]$ and that women care more about the environment [34]. Another explanation could be that these groups are more inclined to agree when using rating scales (so-called 'yeasaying', see [81]). In the latter case, the addition of these variables controls for this measurement bias. The observed effects may be the result of a combination of the two explanations mentioned. Further, an additional analysis that includes an interaction between age and gender showed that older men value price higher than other groups (significant at $p<0.01$, full result not shown here). A further noteworthy finding is that more highly educated people place less importance on all preferences for attributes, except for price and economic security, which are not related to education level. These negative relationships may also be partially the result of 'yeasaying'; lower educated respondents are usually more inclined to agree on rating scales [81]. The effects of income seem to be limited: there is only a negative effect on economic security. This finding makes sense given that higher income households generally suffer more economic insecurity than lower income households. The findings by Dominitz and Manski [82] confirmed that less resilient households are more economically insecure An additional analysis (result not shown here) showed that the lowest and highest income groups are somewhat less concerned about spatial impact than the other income groups. Finally, homeownership is positively related to economic security, private costs and discomfort, and spatial impact. A possible explanation is that homeowners are more dependent on these attributes than non-homeowners. Economic security relates to keeping a job, which is important for paying the mortgage. Private costs and discomfort are especially important since homeowners need to make the decision to renovate their houses and pay for it. Finally, a large spatial impact may lead to fears about a lower property value in the neighborhood [83].

\subsection{Model step 2 continued: explaining the use of information sources}

Internal search is adequately predicted by two variables: prior knowledge and environmental attitudes. The relationship with prior knowledge is in line with earlier findings in a number of product domains $[49,84,85]$. People who score high on environmental attitudes are generally also more knowledgeable about the environment and about energy use [86]. This finding explains the positive relationship between environmental attitudes and internal search.

For different product domains, different findings have been reported on the relationship between prior knowledge and the use of external information sources [85]. In this instance, prior knowledge is positively related to the use of interpersonal channels and the WWW. An additional analysis without the socio-demographic variables (results not shown here) also showed that prior knowledge is negatively related to the use of energy companies as an information source, but this effect is largely explained by homeownership. This result implies that as people become more knowledgeable and confident about the topic of energy, they tend to rely more on sources that are independent of energy companies. Energy companies thus mainly inform a person with a low knowledge base and low confidence. Given the lower general concern of people using energy companies as an information source, this indicates that low knowledgeable people are likely to be less concerned about the problem than others, ${ }^{2}$ probably because energy companies in general do not stress the negative characteristics of energy technologies.

Finally, there is a positive relationship between environmental behavior and the use of the WWW as an information source, although this effect is small in terms of the explained variance. These results combine the utilitarian and cognitive views about the relationship between prior knowledge and search. Low knowledgeable individuals rely mostly on energy companies and as their knowledge increases, they switch to other sources such as interpersonal sources and the WWW to find information. ${ }^{3}$

\footnotetext{
${ }^{2}$ This effect is masked in the table by other effects.

${ }^{3}$ We also tested for an inverted U-shaped relationship, but no significant relationship was detected.
} 
The socio-demographic control variables are also directly related to the use of information sources. Age is negatively related to the use of interpersonal channels and the WWW, which is in line with previous findings that older people make less use of external information sources [65]. A new finding is that women are more likely to use mass media as an information source. Apparently, women are more influenced by commercials and advertisements about the subject of energy use than are men. A possible explanation might be found in the evidence provided by Fisher and Dube [87] that women respond more strongly to emotional advertising such as advertisements about the environment or climate change. Men make more use of the WWW; this effect is in line with earlier findings [85]. Education level is positively related to internal search and the use of interpersonal channels, which is in line with the findings by Kiel and Layton [65] and Van Rijnsoever [85]. Income is negatively related to internal search and interpersonal search, although this effect is small in terms of the explained variance. Another new finding is that people who own a house are less likely to consult energy companies directly than people who rent a house. Homeowners rely more on their own experiences through internal search.

\section{Discussion and conclusion}

The aims of this paper were threefold. We first explored which generic attributes of energy technologies exist. Second, preferences for these attributes were related to the use of information sources for gathering information about energy technologies. Finally, a set of variables derived from the literature was used to explain preferences for the attributes of energy technologies. Following these aims, this paper also has three conclusions that can be summarized as follows: (1) five generic attributes of energy technologies were identified; (2) prior knowledge about energy technologies explains the use of information sources; and (3) environmental awareness explains preferences for attributes.

This study also has a number of limitations. First, despite our efforts to make the sample as representative as possible, there was an overrepresentation of women, higher educated people, and homeowners. In addition, the sample contained only 451 respondents, which is too little for generalization. Further, the sample was limited to the Dutch province of Utrecht and not the Netherlands as a whole. However, the aim of the study was the identification of the important attributes of energy technologies. For this purpose, the sample does not need to be exactly representative. The results of this study are not generalizable, but they can be seen as indicative for future studies and debate. Studies that aim to use these attributes in order to determine preferences for energy technologies, however, do need to be representative for the region they wish to study.

Focusing on preferences for the attributes of energy technologies can lead to a more comprehensive picture of public opinion, which may be more directly linked to people's values than preferences for energy technologies. However, our five attributes may not encompass all of the values that respondents attach to a certain technology or the energy system as a whole. Respondents can have positive/negative feelings about energy technologies that are not attached to a specific attribute. Further, respondents may be unaware of how their choices depend on individual attributes [88]; increasing this awareness may enhance the quality of the energy debate. We suggest that in any measurement of public opinion, both the five attributes and the technological alternatives themselves are included. This study identifies and explains the relevant attributes of energy technologies, which can be used as input for further research and debate.
It is important to minimize the theoretical overlap between attributes, because in later analyses, an overlap can lead to an overestimation of the importance of a certain attribute. For example, a respondent who opposes nuclear energy might do so because of the problem of radioactive waste. The production of radioactive waste has at least two undesired attributes: the transportation of the waste and the permanent storage of the waste. The former is a short-term problem, whereas the latter is a long-term problem. Both attributes might have in common that a respondent does not like radioactivity, and are thus they likely to be correlated. Methods such as factor analysis can be used to identify the overlap among characteristics and to reduce the number of items to a set of uncorrelated attribute preferences.

Finally, the relationships described were formulated in a noncausal manner because our research method does not allow for causal inferences. This issue should be taken into account when considering theoretical and policy implications based on these results.

Based on our results, a number of avenues for further research can be identified. First, the attribute preferences identified can form the basis for further research with regard to the public acceptance of energy technologies. They can be used in qualitative case studies as evaluation criteria. We encourage researchers to apply the attributes in quantitative choice experiments. These attributes can also be used in a conjoint analysis to evaluate their relative importance and thus help establish a ranking of preferred technologies. In this study, respondents provided the highest score to the long-term construct, the risk of catastrophes. It may be interesting to study how people value the attributes in their choices of an energy system that directly affects individual utility in comparison to the attributes that have more impact on society as a whole.

Further, it is important to evaluate whether the public bases its choices on rational attributes only or whether hedonic aspects (such as emotions and reputation) also play a role in evaluating energy technologies. This can be studied using in-depth qualitative methods and linking the preferences for specific attributes to preferences for specific energy technologies. Finally, the current study focused only on energy technologies. However, the method used is also applicable to other technologies. For example, Van Rijnsoever et al. [42] successfully identified three attribute preferences for cars.

Finally, this study has some policy implications. Public acceptance is an increasingly important factor in the energy debate. Instead of focusing on specific technologies, this paper focused on preferences for the attributes of energy technologies that can help decide which set of technologies should comprise future energy systems. The five identified attributes can be seen as a clear set of factors that need to be taken into account by policymakers and other participants in public debate. Next, these attributes can help the public make a well-considered decision about which technology is preferred. As mentioned earlier, these attributes form a point of departure, but they are by no means the only factors to consider in public debate.

The results demonstrated that two underlying factors are important with regard to preference formation: knowing and caring. Knowing (or prior knowledge) is crucial to gathering more information and confidence, while caring (or environmental awareness) promotes making trade-offs between attributes. Both factors are required for the public to formulate well-informed preferences. In order to gain public support for a transition to a new energy system, policymakers and stakeholders need to design strategies to objectively communicate information to the public about the technological options and to give the public the feeling that it is qualified to make a decision about this topic (e.g. increasing the level of confidence). 
Further, awareness about the necessity of an energy transition needs to be increased. Preferably, this awareness should not only focus on environmental aspects, but also focus on other problems such as the security of supply and on the trade-offs that exist between the attributes. The relationships indicated in our model can form a point of departure for these strategies.

Policymakers can also influence the attributes themselves. Some attributes can be influenced by stimulating further technological development (e.g. reducing the risk of catastrophes), while other attributes can be influenced by other policy measures. For example, in many countries solar power is subsidized, but it may require a lot of individual effort to obtain these subsidies.

Taking the results of this study into account may enable a transition towards a future energy system that balances the risk of catastrophes, economic security, private costs and discomfort, spatial impact, and price in such a way as to ensure maximum public support. Policymakers should realize, however, that these preferences are heterogeneously distributed among the population [89]. It is therefore impossible to find a solution that satisfies everyone completely.

\section{References}

[1] European Union. The climate action and renewable energy package, Europe's climate change opportunity; 2009.

[2] Campbell CJ, Laherrere JH. Preventing the next oil crunch - the end of cheap oil. Sci Am 1998;278:77-83.

[3] Morse EL, Richard J. The battle for energy dominance. Foreign Affairs 2002;81:16

[4] van Alphen K, van Ruijven J, Kasa S, Hekkert M, Turkenburg W. The performance of the Norwegian carbon dioxide, capture and storage innovation system. Energy Policy 2009;37:43-55.

[5] Hekkert MP, Suurs RAA, Negro SO, Kuhlmann S, Smits REHM. Functions of innovation systems: a new approach for analysing technological change. Technol Forecast Soc Change 2007:74:413-32.

[6] Hekkert MP, Harmsen R, de Jong A. Explaining the rapid diffusion of Dutch cogeneration by innovation system functioning. Energy Policy 2007;35:4677-87.

[7] Wüstenhagen R, Wolsink M, Burer MJ. Social acceptance of renewable energy innovation: an introduction to the concept. Energy Policy 2007;35:2683-91.

[8] Gibbons M, Limoges C, Nowotny H, Schawartzman S, Scott P, Trow M. The new production of knowledge: the dynamics of science and research in contemporary societies. London: Sage; 1994.

[9] Hessels LK, van Lente H. Re-thinking new knowledge production: a literature review and a research agenda. Res Policy 2008;37:740-60.

[10] Nahuis R, van Lente $H$. Where are the politics? Perspectives on democracy and technology Sci Technol Hum Values 2008;33:559-81.

[11] Brulle RJ. From environmental campaigns to advancing the public dialog: environmental communication for civic engagement. Environ Commun 2010;4:82-98

[12] Colombo S, Angus A, Morris J, Parsons DJ, Brawn M, Stacey K, et al. A comparison of citizen and expert preferences using an attribute-based approach to choice. Ecol Econ 2009;68:2834-41.

[13] Owens S. 'Engaging the public': information and deliberation in environmental policy. Environ Plann A. 2000;32:1141-8.

[14] Firestone J, Kempton W. Public opinion about large offshore wind power: underlying factors. Energy Policy 2007;35:1584-98.

[15] Raven RPJM. Jolivet E, Mourik RM, Feenstra YCFJ. ESTEEM: managing societal acceptance in new energy projects: a toolbox method for project managers. Technol Forecast Soc Change 2009;76:963-77.

[16] Van Alphen K, Voorst QVT, Hekkert MP, Smits REHM. Societal acceptance of carbon capture and storage technologies. Energy Policy 2007;35:4368-80.

[17] Söderholm P, Ek K, Pettersson M. Wind power development in Sweden: global policies and local obstacles. Renew Sustain Energy Rev 2007;11:365-400.

[18] Wolsink M. Wind power implementation: the nature of public attitudes: equity and fairness instead of 'backyard motives'. Renew Sustain Energy Rev 2007:11:1188-207.

[19] Kraxner F, Yang J, Yamagata Y. Attitudes towards forest, biomass and certification - a case study approach to integrate public opinion in Japan. Bioresour Technol 2009:100:4058-61.

[20] Susaeta A, Alavalapati J, Lal P, Matta JR, Mercer E. Assessing public preferences for forest biomass based energy in the southern United States. Environ Manage 2010;45:697-710.

[21] Labay DG, Kinnear TC. Exploring the consumer decision-process in the adoption of solar-energy systems. J Consum Res 1981;8:271-8.

[22] Bickerstaff K, Lorenzoni I, Pidgeon NF, Poortinga W, Simmons P. Reframing nuclear power in the UK energy debate: nuclear power, climate chang mitigation and radioactive waste. Public Understanding Sci 2008;17:145-69.
[23] Corner A, Venables D, Spence A, Poortinga W, Demski C, Pidgeon N. Nuclear power, climate change and energy security: exploring British public attitudes. Energy Policy 2011;39:4823-33.

[24] Bergmann A, Hanley M, Wright R. Valuing the attributes of renewable energy investments. Energy Policy 2006;34:1004-14.

[25] Borchers AM, Duke JM, Parsons GR. Does willingness to pay for green energy differ by source? Energy Policy 2007;35:3327-34.

[26] Zoellner J, Schweizer-Ries P, Wemheuer C. Public acceptance of renewable energies: results from case studies in Germany. Energy Policy 2008;36: 4136-4141.

[27] Bergmann A, Colombo S, Hanley N. Rural versus urban preferences for renewable energy developments. Ecol Econ 2008;65:616-25.

[28] Erbil AÖ. Social acceptance of the clean energy concept: exploring the clean energy understanding of Istanbul residents. Renew Sustain Energy Rev 2011;15:4498-506

[29] McGowan F, Sauter R. Public opinion on energy research: a desk study for the research councild. Brighton: SPRU, University of Sussex; 2005.

[30] Polatidis H, Haralambopoulos DA. Renewable energy systems: a societal and technological platform. Renew Energy 2007;32:329-41.

[31] Hensher DA, Rose JD, Greene WH. Applied choice analysis: a primer. Cambridge: Cambridge University Press; 2005.

[32] Payne JW, Bettman JR, Schkade DA. Measuring constructed preferences: towards a building code. J Risk Uncertainty 1999;19:243-70.

[33] de Best-Waldhober M, Daamen D, Faaij A. Informed and uninformed public opinions on $\mathrm{CO}_{2}$ capture and storage technologies in the Netherlands. Int J Greenhouse Gas Control 2009;3:322-32.

[34] Diamantopoulos A, Schlegelmilch BB, Sinkovics RR, Bohlen GM. Can sociodemographics still play a role in profiling green consumers? A review of the evidence and an empirical investigation J Bus Res 2003;56:465-80.

[35] Gilg A, Barr S, Ford N. Green consumption or sustainable lifestyles? Identifying the sustainable consumer Futures 2005;37:481-504.

[36] Kern F, Smith A. Restructuring energy systems for sustainability? Energy transition policy in the Netherlands Energy Policy 2008;36:4093-103.

[37] UN-ECE. Clearing the air: 25 years of the convention on long-range transboundary air pollution. In: Sliggers J, Kakebeeke W, editors. Geneva: United Nations Economic Commission for Europe; 2004.

[38] Damian M. Nuclear power: the ambigious lessons from history. Energy Policy. 1992;20:596-607.

[39] EC. Green paper. A European strategy for sustainable, competitive and secure energy. Brussels: Commission of the European Communities; 2006.

[40] Windrum P. Ciarli T, Birchenhall C. Environmental impact, quality, and price: consumer trade-offs and the development of environmentally friendly technologies. Technol Forecast Soc Change 2009;76:552-66.

[41] European Commission. Special Eurobarometer. Attitudes of European citizens towards the environment. Eurobarometer. Brussels, Belgium: European Commission, DG Environment; 2008.

[42] Van Rijnsoever FJ, Farla J, Dijst MJ. Consumer car preferences and information search channels. Transp Res D: Transp Environ 2009;14:334-42.

[43] Ben-Akiva M, Morikawa T, Shiroishi F. Analysis of the reliability of preference ranking data. J Bus Res 1991;23:253-68.

[44] Leiserowitz A. Climate change risk perception and policy preferences: the role of affect, imagery, and values. Climatic Change 2006;77:45-72.

[45] Zhang S, Markman AB. Processing product unique features: alignability and involvement in preference construction. J Consum Psychol 2001;11:13-27.

[46] Blackwell RD, Miniard PW, Engel JF. Consumer behavior. Fort Worth: Harcourt College Publishers; 2001.

[47] Aversi R, Dosi G, Fagiolo G, Meacci M, Olivetti C. Demand dynamics with socially evolving preferences. Ind Corporate Change 1999;8:353-408.

[48] Ajzen I. Attitudes, personality and behavior. 2nd ed.. Berkshire, England: Open University Press; 2005.

[49] Kerstetter D, Cho MH. Prior knowledge, credibility and information search. Ann Tourism Res 2004;31:961-85.

[50] Park CW, Mothersbaugh DL, Feick L. Consumer knowledge assessment. J Consumer Res 1994:21:71-82.

[51] Mattila AS, Wirtz J. The impact of knowledge types on the consumer search process - an investigation in the context of credence services. Int J Serv Ind Manage 2002;13:214-30.

[52] Brucks M. The effect of product class knowledge on information search behavior. J Consumer Res 1985;12:1-16.

[53] Alba JW, Hutchinson JW. Knowledge calibration: what consumers know and what they think they know. J Consumer Res 2000;27:123-56.

[54] Brenner LA, Koehler DJ, Liberman V, Tversky A. Overconfidence in probability and frequency judgments: a critical examination. Org Behav Hum Decision Processes 1996;65:212-9.

[55] Park CW, Lessig VP. Familiarity and its impact on consumer decision biases and heuristics. J Consumer Res 1981;8:223-31.

[56] Ellen PS. Do we know what we need to know? Objective and subjective knowledge effects on pro-ecological behaviors J Bus Res 1994;30:43-52.

[57] Schmidt JB, Spreng RAA. Proposed model of external consumer information search. J Acad Mark Sci 1996;24:246-56.

[58] Ratchford BT, Talukdar D, Lee MS. The impact of the Internet on consumers' use of information sources for automobiles: a re-inquiry. J Consumer Res 2007;34:111-9.

[59] Johnson EJ, Russo JE. Product familiarity and learning new information. Consumer Res 1984:11:542-50. 
[60] Kellstedt PM, Zahran S, Vedlitz A. Personal efficacy, the information environment, and attitudes toward global warming and climate change in the United States. Risk Anal 2008;28:113-26.

[61] Grob AA. Structural model of environmental attitudes and behavior. J Environ Psychol 1995;15:209-20.

[62] Widegren O. The new environmental paradigm and personal norms. Environ Behav 1998;30:75-100.

[63] Dunlap RE, Van Liere KD, Mertig AG, Jones RE. Measuring endorsement of the new ecological paradigm: a revised NEP scale. J Soc Issues 2000:56:425-42.

[64] Klein LR, Ford GT. Consumer search for information in the digital age: an empirical study of pre-purchase search for automobiles. J Interactive Market 2003;17:29-49.

[65] Kiel G, Layton RA. Dimensions of consumer information seeking behavior. J Market Res 1981;18:233-9.

[66] Gursoy D, McCleary KW. An integrative model of tourists' information search behavior. Ann Tourism Res 2004;31:353-73.

[67] Van Rijnsoever FJ, Castaldi C, Dijst MJ. In what sequence are information sources consulted by involved consumers? The case of automobile prepurchase search J Retailing Consumer Serv 2012;19:343-52.

[68] Van Rijnsoever FJ, Castaldi C. Extending consumer categorization based on innovativeness: intentions and technology clusters in consumer electronics. J Am Soc Inf Sci Technol 2011;62:1604-13.

[69] Saviotti PP, Metcalfe JSA. Theoretical approach to the construction of technological output indicators. Res Policy 1984;13:141-51.

[70] Castaldi C, Fontana R, Nuvolari A. 'Chariots of fire': the evolution of tank technology, 1915-1945. J Evol Econ 2009.

[71] Frenken K, Leydesdorff L. Scaling trajectories in civil aircraft (1913-1997). Res Policy 2000;29:331-48

[72] Jaccard J, Brinberg D, Ackerman LJ. Assessing attribute importance: a comparison of six methods. J Consumer Res 1986;12:463-8.

[73] Jöreskog K, Sörbom D. LISREL. 8.80. Scientific Software International, Inc: 2006.

[74] Flynn LR, Goldsmith RE. A short, reliable measure of subjective knowledge. J Bus Res 1999;46:57-66.
[75] CBS. Houses after ownership and municipality. Statistics Netherlands; 2008.

[76] Slovic P. Perception of risk. Science 1987;236:280-5.

[77] Allen SR, Hammond GP, McManus MC. Prospects for and barriers to domestic micro-generation: a United Kingdom perspective. Appl Energy 2008;85: 528-544.

[78] Preacher KJ. Testing complex correlational hypotheses with structural equation models. Struct Eqn Model Multidiscip J 2006;13:520-43.

[79] Finucane ML, Slovic P, Mertz CK, Flynn J, Satterfield TA. Gender, race, and perceived risk: the 'white male' effect. Health Risk Soc 2000;2:159-72.

[80] Slovic P. Trust, emotion, sex, politics, and science: surveying the riskassessment battlefield. Risk Anal 1999;19:689-701.

[81] Greenleaf EA. Improving rating-scale measures by detecting and correcting bias components in some response styles. J Market Res 1992;29:176-88.

[82] Dominitz J, Manski CF. Perceptions of economic insecurity: evidence from the survey of economic expectations. Public Opin Q 1997;61:261-87.

[83] Sims S, Dent P, Oskrochi GR. Modelling the impact of wind farms on house prices in the UK. Int J Strategic Property Manage 2008;12:251-69.

[84] Punj GN, Staelin R. A model of consumer information search behavior for new automobiles. J Consumer Res 1983;19:363-80.

[85] Van Rijnsoever FJ. Consumers in demand: the relationship between innovativeness and use of information sources. PhD thesis. Utrecht: Utrecht University; 2010.

[86] Arcury TA. Environmental attitude and environmental knowledge. Hum Org 1990:49:300-4.

[87] Fisher RJ, Dube L. Gender differences in responses to emotional advertising: a social desirability perspective. J Consumer Res 2005;31:850-8.

[88] Verlegh PWJ, Schifferstein HNJ, Wittink DR. Range and number-of-levels effects in derived and stated measures of attribute importance. Market Lett $2002 ; 13: 41-52$

[89] Windrum P, Ciarli T, Birchenhall C. Consumer heterogeneity and the development of environmentally friendly technologies. Technol Forecast Soc Change 2009;76:533-51. 